\title{
Business game as a method of development of skills of communication in the professional focused training in foreign languages in technical universities.
}

Turin polytechnic university in Tashkent

Anush Tsakanyan, $\mathrm{PhD}$

Sultan Gadjiev, senior teacher

One of the ways to develop communication skills is to implement business games in the educational process in technical universities. For that reason, it is necessary to define the purposes and problems of a business game, a plot of a business game, the structure of game groups, speech material of a game taking into account level of training of students. A business game intensifies educational process, imitates conditions of professional activity of future experts, promoting formation of skill of work in team.

Key words: business game, communication, professional orientation, special terminology, vocational education, relevant directions.

At the present stage, professional education provides training of specialists not only in special objects, but also achievement by students of a certain level of proficiency in a foreign language. According to program requirements, a priority problem of the subject "Foreign language" in technical college is training in communication at a foreign language. For the fullest professional education, training in the professional focused communication at a foreign language is one of the relevant and perspective directions of development of professional education. As the basic principles of training in professional communication in a foreign language, it is possible to allocate the following: the professional orientation meaning extensive knowledge of special terminology, communicativeness and country study aspect. 
To fulfill the program requirements, it is necessary to intensify educational process due to application of effective methods of training. Knowledge of a foreign language is a component of vocational training of the expert and one of prerequisites of his further successful work. For this purpose it is necessary to develop communication skills in a foreign language in professionally significant aspects.

Modern pedagogical technologies for training in language of specialty allow to bring educational process closer to professional activity. For some decades, active forms and methods have already been used in vocational education. However, the advanced methods in the conditions of a higher education institution are used insufficiently now. It is necessary to intensify educational process, to introduce active methods of training in the professionally focused communication in a foreign language.

One of the effective methods of training in the professionally focused communication in a foreign language in technical higher educational institutions is a business game which allows to break successfully psychological and speech barriers in business communication situations and promotes formation of communicative competence of a future expert.

We understand a complex of the situations united by methodically uniform scenario which is a form of the organization, training and control of collective educational activity as a business game.

Business game can be presented in the form of several stages of joint activity of the teacher and students: a) preparation for a business game and its carrying out $b$ ) realization of goals and discussion.

Preparation for holding a business game has to include work on lexical and grammatical material. In the course of preparation and holding a game important functions are performed by the teacher. The teacher faces the following main objectives: selection of language and speech material for a game subject, creation 
of the business game scenario, the organization professionally oriented training of speech of students. The efficiency of educational process with the use of a business game depends on technology of creation of methodologically correct scenario and its application in the course of training. At the same time, it is necessary to define the purposes and problems of a business game, a plot of a business game, the structure of game groups, speech material of a game taking into account level of training of students. A business game intensifies educational process, imitates conditions of professional activity of future experts, promoting formation of skills in teamwork.

Besides, a business game in a foreign language can be used as a method of training and as a control method at the end of studying of a subject. It can be applied at various grade levels in higher education institution, also lexical, grammatical, conditional and speech and speech exercises can precede it.

It is expedient to write down role-playing game on video. The video allows at a discussion stage in groups to analyze speech behavior of participants of a game, their action, manner to behave, a mimicry, gestures, official style of clothes.

Besides, a business game in a foreign language can be used and as a control method. Control of assimilation is exercised in pair work of students in the form of playing of mini-situations. At the same time much attention is paid to the correct lexical and grammatical structure of phrases. Students at first acquire speech clichés and lexical material in mini-dialogues in which specific speech objectives, and then in the tasks of communicative character more difficult on structure and the contents are implemented.

In terms of prospects in training, the last stage - a stage of discussion of a game is especially important. At this stage of a business game the communicative competence of participants of a game is subject to the analysis and also the assessment of separate situations and a game in general is carried out. 
Besides, the general discussion it would be expedient to conduct individual survey in writing where students could estimate a business game as a way of training in the professional focused communication in a foreign language.

However, possession of a certain lexicon, grammatical and speech skills does not guarantee success in business communication yet. For successful business communication, it is necessary to know features of the country of the learned language. Acquaintance to mentality of the people, rules of holding business meetings and business communication help to avoid misunderstanding and the inconvenient moments in communication with foreign partners.

Business game is one of the types of educational games, used to solve complex problems of mastering new information, consolidation of material, development of creative abilities and the formation of general educational skills. It allows students to understand and study the learning material from different positions. The game helps to improve the knowledge of students, develops interest in the subject, research and creative skills of students, allows the graduate to form both general and professional competence. Business games, developed on specific situations, introduce students to the sphere of professional activity, develop their ability to critically assess the current situation, find solutions for its improvement, are a powerful incentive to enhance independent work on the acquisition of professional knowledge and skills. The practical skills acquired during the game allow the future specialist to avoid mistakes that arise during the transition to selfemployment.

Students enjoy the game, there is a high motivation, emotional saturation of the training process. During "the business game" there is some preparation for professional activity, knowledge and skills are formed. At this moment, in our opinion, the level of presentation use at a lesson sharply increases, the labor productivity of the teacher and student increases as well. Inter-subject connections with educational and special disciplines also play significant role, they allow students to gain stronger knowledge in several objects at once. The consideration 
of students about the personal computer not as an entertainment gadget, but as the universal tool for work in any sphere of human activity changes. At this technology of conducting a lesson, great attention is paid to logical training material delivery that considerably increases the level of students' knowledge. Application of the "business game" method at lessons yields the positive result: students participate in all competitions of professional skill more actively, moreover, they show higher interest to their future profession.

As a business game in a foreign language is a new way of training for the students, there is a need of removal of some psychological difficulties. It is for this purpose recommended to hold during preparation for the most business game the mini-games representing one or two situations with the subsequent short analysis and correction of mistakes. Cast is recommended to be provided to students, having pointed out at the same time features of roles and situations. The role of the teacher in the most business game if the business game is held for the first time, comes down to a role of the consultant or coordinator of actions of students. In the subsequent games it is necessary to provide to students more independence in organizational issues. The teacher should encourage an initiative, the independent and creative relation of students to the charged role.

On the basis of the above it is possible to draw a conclusion that scientifically and methodically reasonable use of business games is an active and effective method of training in the professional focused communication in a foreign language and means of an intensification of educational process, allows to break successfully psychological and linguacultural barriers in situations of business communication in a foreign language and leads to formation of communicative competence.

Conclusion. The technology of business games aimed at teaching professional communication has a number of features. Business game should be based on real speech material that reflects the specific situation of communication in the professional sphere. The moment of self-study dominates over training in the 
business game as well. This is because a foreign language teacher might be incompetent in matters of the students' specialty and cannot make a business game and evaluate its communicative (not language) results without their help competently. Therefore, students are involved in the business game preparation and its assessment, according to the result if the communicative aim has been achieved or not.

Reference:

1. Aldrich, Clark (2004), Simulations and the Future of Learning, San Diego: Pfeiffer

2.Brown G., 2012 "Reading Comprehension" the teaching comprehension. London: The British Council.

3. Hymes D., 2014 "Towards ethnographies of Communicative Events".

4. Ch. Kennedy, P.Doyle 2009 "Exploring Change in English Language Teaching", London. Macmillan.

5. S. Sheerin 2010. "Teaching English for Specific Purposes".

6. Saunders, Danny (1996), Games and Simulations to Enhance Quality Learning; Volume 4 of International Simulation and Gaming Yearbook, Psychology Press 